\title{
SARTRE POR BARBARAS: MOVIMENTOS DE UMA LEITURA CRÍTICA
}

\author{
Sartre by Barbaras: movements of a critical reading
}

Sartre por Barbaras: movimientos de una lectura critica

\begin{abstract}
Resumo: Neste trabalho nos propomos a apresentar alguns movimentos da leitura crítica que Renaud Barbaras realiza da filosofia de Sartre. Para tal, escolhemos como fio condutor a retomada que este autor faz do dualismo de base da filosofia sartriana, em continuidade com a crítica de Merleau-Ponty, porém de modo a abrir outros caminhos de reflexão. Gostaríamos de evidenciar nestes caminhos o quanto Barbaras não somente potencializa a crítica precedente, mas realiza aproximações e problematizações originais que, ao mesmo tempo em que tornam mais evidentes os impasses da filosofia sartriana, não deixam de abrir novas possibilidades de investigação. Estas últimas nuances serão apontadas através da crítica propriamente barbarasiana da questão do outro e do desejo em Sartre.
\end{abstract}

Palavras-chave: Dualismo; Negatividade; Desejo; Outro; Facticidade.

\begin{abstract}
In this work we propose to present some movements of the critical reading that Renaud Barbaras performs of Sartre's philosophy. For this, we have chosen as the guiding thread the author's reiteration of the basic dualism of Sartre's philosophy, in alignment with Merleau-Ponty's critique, but seeking to open other paths of reflection. We would like to point out in these paths that not only does Barbaras enhance the preceding critiques, but makes original approaches and problematizations, which makes the impasses of Sartre's philosophy more evident while also opening new possibilities for investigation. These later nuances will be pointed out through a properly Barbarasian critique of the question of the other and the of the desire in Sartre.
\end{abstract}

Keywords: Dualism; Negativity; Desire; Other; Facticity.

Resumen: En este trabajo nos proponemos presentar algunos movimientos de la lectura crítica que Renaud Barbaras realiza de la filosofía de Sartre. Para eso escogimos, como hilo conductor, la recuperación que este autor hace del dualismo de base de la filosofía sartriana, en continuidad con la crítica de Merleau-Ponty, como modo de abrir otros caminos de reflexión. En estos caminos nos gustaría evidenciar la manera en que Barbaras no solo potencializa la crítica precedente sino el modo en que realiza aproximaciones y problematizaciones originales, que al mismo tiempo en que tornan más evidentes los impases de la filosofía sartriana, no dejan de abrir nuevas posibilidades de investigación. Estos últimos matices son puntuados a través de la crítica propiamente barbarasiana de la cuestión del otro y el deseo en Sartre.

Palabras clave: Dualismo; Negatividad, Deseo; Otro, Facticidad.

Não há outro modo de pensar o movimento em sua verdade que efetuá-lo ${ }^{1}$ Renaud Barbaras, De l'être du phénomène

\section{Introdução}

De um modo geral, é certo dizer que Renaud Barbaras é um crítico de Sartre, no sentido de apontar sobretudo os problemas, fracassos e impasses de sua filosofia. Além disso, sendo Barbaras uma referência nos estudos merleau-pontyanos, juntamente com reconhecimento de sua própria filosofia, é natural que se atribua uma espécie de continuidade entre as posições de Merleau-Ponty e as suas próprias com relação a Sartre. E isto se reforça por duas razões: em primeiro lugar, dado que Barbaras de fato retoma a crítica merleau-pontyana numa escrita que vai além do comentário, radicalizando-a ou pontencializando-a; em segundo lugar, já que ele se opõe, no curso do desenvolvimento de sua filosofia, a problemas

1 Todas as traduções são livres. sartrianos já apontados por Merleau-Ponty - quem, por sua vez, desenvolveu grande parte de seu pensamento a partir desse contraponto - embora para colocá-los de outros modos, encontrar novas soluções, por caminhos diversos. Assim, não é somente em termos de continuidade e pontencialização da crítica de Merleau-Ponty que podemos compreender a leitura de Sartre por Barbaras. Na verdade, há movimentos que vão além dos pontos anteriormente colocados; movimentos que não se restringem simplesmente à caracterização de um endereçamento frontal de oposição e refuta, dado que apresentam nuances que valem a pena ser evidenciadas a fim de compreender a relação entre os autores, assim como os pontos de tensão da própria filosofia de Sartre. Neste sentido, mais do que apresentar exaustivamente a crítica de Barbaras a Sartre, ou mesmo de colocá-la à prova, testando sua validade, suas contradições, etc., pretendemos mostrar sobretudo a dinâmica de uma relação composta de aproximações, distanciamentos, condenações, aberturas de possibilidades, entre 
outros modos que caracterizam uma movimentação viva que é o traço singular da retomada de um autor como experiência do pensamento.

\section{Potencializando a crítica de Merleau-Ponty: o dualismo de base da filosofia sartriana.}

Ao leitor que busca compreender os elementos em jogo na crítica de Merleau-Ponty a Sartre em $O$ Visível e o invisível, o capítulo três da Segunda Parte - "Etre et Néant : la dialectique" - de De l'être du phénomène de Barbaras (2001) é esclarecedor, embora com isso não devamos concluir que ele seja apenas um comentário. Nele, o movimento do autor acaba por mostrar a crítica merleau-pontyana radicalizada e potencializada. O posicionamento de concordância com Merleau-Ponty é assim bastante claro: Barbaras concorda que Sartre não consegue ultrapassar os impasses e limitações das filosofias reflexivas e que sua concepção de sujeito para-si como nada é problemática. Em seus termos, ele radicaliza a posição merleau-pontyana de que a filosofia do negativo de Sartre resulta numa filosofia de sobrevôo, da qual provém uma concepção de sujeito que finalmente não pertence ao mundo. Mas a maneira pela qual o autor nos conduz a tais conclusões é bastante própria, mostrando que Sartre até se aproxima de Merleau-Ponty num tipo de contraposição a Husserl, mas para oferecer uma solução diferente. Para Barbaras, na tentativa de pensar uma unidade do ser e do nada na experiência de abertura ao mundo, tal como o faz Merleau-Ponty, Sartre parte de uma oposição radical entre os termos que renova o dualismo ao mesmo tempo em que o supera. Isto ocorre porque Sartre não consegue pensar uma mistura efetiva no que é colocado de antemão como oposto, de modo que a relação entre para-si e em-si só pode ser pensada num plano lógico, e não como experiência concreta. Escreve Barbaras, concordando com Merleau-Ponty:

Na realidade, esta filosofia [de Sartre] só nos dá o "retrato abstrato de uma experiência" (Merleau-Ponty citado por Barbaras, 2001): ela incorpora ao para si e ao em si a passagem de um a outro que a experiência atesta, mas o movimento mesmo desta experiência não é restituído. A passagem não pode ser efetiva uma vez que, sob os termos de Ser e de nada, a fixidez das categorias reflexivas é mantida: ela só se completa ao preço de renovar a oposição (Barbaras, 2001, p.140).

Mas o que está em jogo nas "filosofias reflexivas", de modo que o caminho para ultrapassá-las se torna uma armadilha para Sartre? Merleau-Ponty (2013) mostra que este último se opõe ao quadro reflexivo que presumia uma positividade interior e tratava o fora como simples negativo, propondo um espírito como puro negativo e logo, o ser como exterior e como pura positividade. Assim, uma simples inversão entre as esferas positiva e negativa não supera o dualismo, do mesmo modo que Heidegger (2008) dizia que "a inversão de uma proposição metafísica permanece uma proposição metafísica” (p. 85).
Sobre as filosofias reflexivas, Barbaras aponta a recusa merleau-pontyana de uma cisão que este autor identifica na filosofia de Descartes entre um plano irrefletido da vida e um plano reflexivo das ciências, assim como a divisão husserliana entre os planos da atitude natural e o plano desvelado pela atitude transcendental. Merleau-Ponty busca pensar uma unidade que permita pensar a abertura ao mundo, de forma que

[...] longe de se confundir com um contato cego com o em si, ela aparece como o começo da reflexão [...] inversamente, deve-se definir a reflexão não como procedendo de uma esfera positiva e autônoma do ponto de vista a partir do qual a ordem do irrefletido seria definitivamente incompreensível, mas como aquilo que tira sua possibilidade do próprio irrefletido. Em suma, trata-se de mostrar como "entrar em si" é do mesmo modo "sair de si" (Barbaras, 2001, p. 135).

Colocado deste modo tal dualismo, a inversão que instaura a primazia do irrefletido em Sartre traz consigo a manutenção da divisão de planos, embora esvazie o sujeito de toda positividade, caracterizando-o como puro nada. É neste ponto que Barbaras mostra como Merleau-Ponty e Sartre, após se aproximarem brevemente na identificação de um problema, seguem rumos diversos e decisivos em suas filosofias. Ambos criticam uma espécie de "substancialização" da subjetividade husserliana, a qual impede o próprio movimento da consciência intencional - uma crítica que Barbaras identifica e desenvolve como crítica à "positividade da essência" em Husserl (2001, p. 137). Em La Perception, este ponto é esclarecido a partir da pergunta: "como uma vivido imanente poderia fazer aparecer uma transcendência, quer dizer, fazer afinal com que a consciência saia dela mesma [?] Não há uma dificuldade ao pensar como conteúdo de consciência o ato sobre o qual repousa a relação da consciência a seu outro?" (Barbaras, 2009, p. 71). Sartre (2012), por sua vez, colocava uma questão de certo modo próxima na "Introdução" de O Ser e o Nada ao dizer que Husserl prefere reduzir o ser ao "não ser", fazer dele um noema "irreal", instaurando finalmente a realidade $(r e e l)^{2}$ na plenitude subjetiva. Neste sentido, Sartre afirma que esta subjetividade "não poderia sair de si para posicionar um objeto transcendente" (p. 27) já que a realidade do objeto funda-se sobre a plenitude subjetiva e sua objetividade é um não ser, de modo que "jamais o objetivo sairá do subjetivo, nem o transcendente da imanência, nem o ser do não ser” (p. 27-28). O ponto de proximidade que identificamos nessas questões corresponde à crítica de um imanentismo da subjetividade husserliana que acaba por admitir "conteúdos", embora Sartre logo direcione sua crítica ao noema enquanto Barbaras (2009) a restringe ao próprio vivido (le vécu). Para este último, Husserl faz do vivido um ser positivo e não respeita a evanescência própria do aparecer, o que o leva de alguma maneira a interiorizar o empirismo e o intelectualismo

2 Husserl estabelece uma distinção entre Real e Realität, que corresponde à realidade natural, mundana, e Reel, que abrange a realidade da esfera imanente dos vividos. Cf. Husserl, 2013, p. 553. 
no "bojo da consciência transcendental sob a forma da dualidade e da unidade por fim incompreensível da matéria e da forma” (p. 72). No entanto, Barbaras considera que a teoria dos perfis de Husserl, ao contrário da crítica de Sartre, é justamente aquela que legitima a transcendência: "Se uma coisa (um “alguma coisa”) é de fato uma realidade transcendente, ou seja, se distingue de meus vividos, ela só será presente como alguma coisa com a condição de não ser inteiramente presente, de diferir de uma doação adequada, de resistir à apropriação” (p. 58).

Sartre não vê do mesmo modo este aspecto sublinhado por Barbaras sobre a teoria dos perfis de Husserl. Enquanto Sartre considera finalmente que a subjetividade husserliana, assim como o "espírito-aranha" - que é o modo pelo qual ele caracteriza as filosofias idealistas que trazem toda realidade transcendente para seu interior (Sartre, 1989) - admite a imanência de conteúdos na subjetividade pura, transformando o ser percebido em seu correlato, Barbaras (2009) acentua que é justamente a doação por perfis que faz com que a coisa percebida escape ao conhecimento que se pode ter dela, visto que ela "excede toda experiência que possa ser feita dela, e este excesso é sem medida, a distância (l'écart) entre a coisa e sua percepção singular não poderia ser reduzida” (p. 64). O ponto que Barbaras considera ser de extrema importância na teoria de Husserl não é compreendido deste modo por Sartre (2012), já que este último censura o fato das aparições serem reduzidas a uma "matéria impressional (impressionnelle) subjetiva” (p. 27), de modo que, se Husserl define a consciência como transcendência e faz do ser um "ser percebido", ele é "totalmente infiel a seu princípio” (p. 28). Assim, na medida em que Sartre não considera a teoria dos perfis como via de contestação do idealismo e legitimação da esfera transcendente, ele busca a saída destes problemas através da "transfenomenalidade" dos modos de ser para-si e em-si. O para-si é então engajado na transcendência no sentido de escapar a uma filosofia husserliana contemplativa, a qual pressupõe uma concepção da consciência como uma esfera hipostasiada da subjetividade. A este engajamento Sartre dá o nome de "prova ontológica”, que consiste numa versão particular do princípio de intencionalidade da consciência: "A consciência é consciência de alguma coisa: isto significa que a transcendência é a estrutura constitutiva da consciência; quer dizer que a consciência nasce apoiada sobre (portée sur) um ser que ela não é” (p. 28). Isto significa, diz ainda Sartre, que a consciência é "intuição revelante" de algo que não é ela, e que esta intuição não é uma relação de conhecimento, mas de ser. A consciência só existe como revelação de algo e implica "em seu ser um ser não consciente e transfenomenal” (p. 28, grifo nosso); ela existe apenas através desta intuição revelante do ser, por uma relação que Sartre denomina de negação interna, de modo que não é possível pensar uma subjetividade apartada desta relação negativa. Por outro lado, o ser a partir do qual a consciência existe como “intuição revelante" é o ser transfenomenal dos fenômenos que, não podendo ser imanente a consciência, deve ser ele mesmo em-si. Neste aspecto Sartre se distancia de posições fundamentais de Husserl, chegando a ser mesmo seu contraponto, diz Barbaras (2005), uma vez que ele esvazia a consciência e restitui ao objeto sua realidade: "Assim, Sartre opõe o vazio da consciência à plenitude impressional dos vividos, e a densidade do em-si a um não ser do objeto. Ele atribui à consciência a falta pela qual Husserl definia o objeto e ao em-si a plenitude pela qual Husserl caracterizava o subjetivo" (p. 139). Eis então um outro modo de descrever uma "inversão" sartriana. Das consequências significativas deste gesto pode-se destacar uma recaída de Sartre ao mesmo tempo no realismo e no idealismo, dicotomia que ele pretendia superar na "Introdução" de O Ser e o Nada. A via realista se deve à concepção materialista e positiva de em-si, já que a recusa do idealismo neste caso conduz ao esforço de nunca reduzir o ser à sua aparição para a consciência, de modo que ele qualifica o ser dos fenômenos - ser em-si - de "transfenomenal”. Acontece que, se o em-si escapa de algum modo ao fenomenal, pode-se indagar se esta ontologia mantém de fato seu estatuto fenomenológico, já que admite certo realismo não fenomenal. Este ponto é levantado por Barbaras (2005) no texto "Désir et manque dans L'Être et le Néant: le désir manqué", em que ele questiona tal estatuto. Na medida em que Sartre "coloca o em-si fora de sua fenomenalidade e postula assim uma espécie de independência do em-si com relação ao para-si” (p. 115), isso resulta numa "submissão à atitude natural, comprometendo gravemente a démarche fenomenológica” (p. 135). Finalmente, trata-se de uma "fenomenologia sem fenômenos", visto que

[...] ao falar do em-si, Sartre logo introduz, por um modo nos fim das contas realista, uma cisão entre o ser e o fenômeno. Ao invés de partir da fenomenalidade como o elemento no seio do qual o sentido do ser do sujeito e do transcendente (em-si) podem ser apreendidos, ele reconstitui, ao contrário, a fenomenalidade a partir da relação entre o para-si e um em-si em repouso. (Barbaras, 2005, p. 136).

A concepção do em-si como pura positividade é assim um contraponto simétrico desta subjetividade esvaziada a ponto de ser caracterizada como um puro nada. Aqui encontramos a outra consequência do gesto sartriano de inversão, conforme mencionamos acima. Barbaras adota a posição de Merleau-Ponty de $O$ Visível e o Invisível de que o problema reside na concepção sartriana de negatividade. Enquanto que Merleau-Ponty se opõe à positividade da essência husserliana ao "descomprimi-la”, buscando voltar ao ponto de inserção da subjetividade no ser, Sartre perde a possibilidade de pensar efetivamente o negativo ao conceber uma negatividade positiva, por mais contraditório que tal termo possa ressoar ${ }^{3}$. Tal negatividade positiva é para Merleau-Ponty - e também para Barbaras - o nada (néant) sartriano. A

3 Barbaras (2001) explica que Merleau-Ponty critica mais a "positividade" da essência husserliana do que propriamente a essência, o que o faz preservar a dimensão de significação. Enquanto que Sartre nega a essência em nome de uma ideia de nada que herda, na verdade, sua positividade. Ou seja, Sartre estaria atacando a essência ao invés de sua positividade, e ao 
diferença entre negatividade e nadidade passa a ser então fundamental para Barbaras, pois é tendo em vista tal diferença que ele irá desenvolver sua concepção do sujeito como movimento, como atesta a obra Dynamique de la manifestation: "O modo de existir que designa a negatividade em sua diferença para com o nada deve então ser definido como movimento" (2013, p. 80). Para Barbaras, o problema não consiste então em pensar o sujeito como negatividade, pois é pela negatividade que a diferença ontológica entre este modo de ser e os outros entes mundanos se faz - neste caso a diferença como movimento -, mas sim em pensar a negatividade como nadidade e, consequentemente, o ente como em-si:

Por um lado, esta passagem do não ente ao nada, ou ainda a subordinação da negatividade à nadidade (néantité) tem por pressuposto uma determinação pobre e, por assim dizer, abstrata do ente. É com efeito porque o ente é compreendido como uma entidade absolutamente densa, idêntica a ela mesma e por isso imutável, como um tipo de super-objeto, à maneira do Ser parmenídico, que sua negação só pode então remeter a um nada absolutamente exterior, a um puro nada que é tão negativo quanto o ser é positivo, que é tão ontologicamente inconsistente quanto o ser era ontologicamente denso. (Barbaras, 2013, p. 77).

Por esta razão, Merleau-Ponty (2013) falava em paralelismo entre ser e nada, pois se o nada é finalmente um tipo de coisa, dado sua reificação, os dois termos são finalmente positivos de modo que a relação entre eles é paralela, frontal e sem movimento ${ }^{4}$. Barbaras acompanha essa crítica em seus resultados, sobretudo no fato de tal paralelismo impedir o movimento próprio de uma dialética. Em seus termos, ele define então a filosofia do negativo de Sartre como uma filosofia da identidade, que não admite diferença. Mesmo que em Sartre um termo só se defina com relação a outro, essa relação é abstrata e não modifica os termos; pelo contrário, ela reforça a identidade de cada um na medida em que o nada só é puro nada enquanto o ser for puro ser:

Ao definir a consciência como nada, Sartre não mostra como ela efetivamente abre ao Ser, ele se contenta em a determinar de maneira que ela não pode ser pensada sem recurso ao Ser: ele evidencia uma necessidade para o pensamento, uma necessidade abstrata, mas não acompanha o movimento efetivo. Trata-se então de conferir a cada termo uma determinação tal que sua identidade só possa se sustentar posicionando o outro termo. Pensar segundo o negativo puro já é ter se dado a identidade ou a positividade; pensar segundo a pura densidade do Ser, é já ter colocado a pura negatividade do nada (Barbaras, 2001, p. 140).

fazê-lo ele descarta a mediação da essência em prol de um contato imediato e frontal com o ser. Cf. p. 144-145.

4 Mostramos com detalhes esta crítica de Merleau-Ponty a Sartre, assim como seus limites em outro artigo: "Limites da crítica de Merleau-Ponty a Sartre em $O$ Visível e o Invisivel" (Alt, 2017b)
Se a relação é, portanto, o operador de reforço da identidade de cada termo consigo mesmo, não há condições para que haja diferença efetiva. Ou seja, permanecemos num plano de oposição lógica realizada pelo pensamento que não alcança o movimento concreto que ocorre na experiência de abertura ao mundo: "a abertura ao mundo é esquematizada sob a forma de uma necessidade do entendimento, que procede da definição prévia dos termos por sua oposição" (Barbaras, 2001, p. 142). Na verdade, enquanto Merleau-Ponty fala de "repouso" dos termos opostos, Barbaras pensa em um movimento caricato, um vai-e-vem esquematizado, razão pela qual Sartre renova o dualismo na tentativa de superá-lo.

Barbaras assume assim e desenvolve a crítica de Merleau-Ponty de modo a potencializá-la, evidenciando os movimentos de inversão de dualismos realizados por Sartre que não o livram de conceber uma filosofia dualista, mas ao contrário atestam sua revitalização. Este gesto de Sartre traz consequências para temas fundamentais de sua filosofia, retomados de forma original por Barbaras como a questão do outro e a concepção de desejo. $\mathrm{O}$ autor se dedica a apresentar tais consequências por um movimento que revela ao mesmo tempo aproximações e distanciamentos, movimento fundamental para o desenvolvimento de sua própria filosofia.

\section{A questão do outro}

Merleau-Ponty já mostrava como o dualismo de base da filosofia sartriana impedia a experiência efetiva de alteridade. Isto porque a divisão que Sartre estabelece entre os modos de ser para-si e para-outro seria consequente da concepção do sujeito como uma esfera pura de nadificação, que só adquire objetividade através do olhar do outro, radicalizando a separação entre os sujeitos e finalmente ratificando o traço solipsista desta filosofia. Assim, ao invés de atestar de fato um "encontro" com o outro, ou uma subjetividade cuja alteridade seria parte constitutiva, Sartre acaba por isolar ainda mais o sujeito em sua esfera "intocável”, através de sua teoria do outro pelo recurso do ser-para-outro. Barbaras (2001) explora essa consequência ao mostrar que "a relação ao outro se confunde com a experiência do para-outro : a consciência não lida jamais com o outro pessoalmente, somente com ela mesma"; e ainda "se o acesso ao outro se confunde com a experiência (l'épreuve) de meu ser-olhado, ele deixa de ser uma experiência, já que não revela algo do qual ele é experiência: ele retorna à descoberta de meu ser-para-outro, quer dizer, a uma estrutura da minha consciência” (2001, p. 159), de modo que, como já concluía Merleau-Ponty, "eu não lido com os outros, eu lido no máximo com um não-eu neutro, com uma negação difusa do meu nada” (2013, p. 99).

Assim como Merleau-Ponty, Barbaras (2001) mostra também o quanto esta teoria do outro encontra-se impregnada dos pressupostos de uma "filosofia da visão", no sentido de uma filosofia de um sujeito não encarnado, que sobrevoa o mundo a ponto de tomá-lo diante de si em panorama, tal como um puro nada em face do ser, desconhecendo a própria 
essência do “ver” (p. 149). Pensar a experiência do outro através do olhar, revela assim a coerência do desdobramento, neste outro plano, da filosofia da visão, na medida ainda que Sartre se atém a um tipo de experiência, a do olhar: "Filosofia da visão, o pensamento do nada se realiza, no plano da experiência do outro, como filosofia do olhar (du regard)" (p. 160), conclui Barbaras.

Para além desta retomada da crítica de Merleau-Ponty, gostaríamos de ressaltar a maneira pela qual Barbaras desenvolve outras consequências da teoria do outro em Sartre. O texto "Le corps et la chair dans la troisième partie de L'Être et le Néant" retoma e reforça estes pontos, mas vai além ao apresentar um movimento interessante do autor: nele, encontramos uma reflexão inovadora e inesperada a respeito do conceito sartriano de carne (la chair). Antes de tocar neste ponto, no entanto, Barbaras (2000) realiza uma longa e rigorosa discussão sobre a teoria sartriana do outro, nos apresentando um texto denso, em cujos detalhes não temos como nos aprofundar aqui ${ }^{5}$. Nos concentraremos então em alguns aspectos, a começar pela organização que o autor apresenta das condições estabelecidas por Sartre sobre a sua teoria do outro: 1) a relação ao outro é interna e não externa (como no conhecimento), trata-se de uma relação de ser; 2) o único ponto de partida possível é a interioridade do cogito; 3) a relação a outrem não pode ser de constituição; o outro não pode ser deduzido de uma estrutura ontológica. Não teremos como pormenorizar todos estes pontos, mas o que ressaltamos aqui é o fato de que Barbaras encontra uma contradição nas condições estabelecidas por Sartre para propor em seguida uma solução ainda sartriana; solução que o próprio Sartre não consegue aproveitar, devido à sua fidelidade ao dualismo inicial. Barbaras mostra então primeiramente como tal dualismo orienta as análises sartrianas sobre o corpo, na medida em que estas dependem da teoria do outro:

A análise de Sartre repousa então inteiramente na oposição cortada entre uma consciência irrefletida que é definida pela imanência pura e uma objetidade que não poderia pertencer ao para-si como tal, que é proveniente do conhecido e, por conseguinte, reenvia ao outro. O para si não tem corpo e, longe de seu ser para-outro proceder de seu pertencimento à exterioridade, é este pertencimento que repousa inteiramente sobre o outro. O para-si se encarna, mais não é enquanto para-si que ele se encarna: se ele é capaz de passar à exterioridade, esta passagem não pertence entretanto à essência da presença a si (Barbaras, 2000, p. 280-281).

Barbaras (2000) entende então que a encarnação do para-si - sua inscrição na exterioridade - só é possível pela via do ser-para-outro. Por esta razão, o fato de Sartre conceber um corpo para-si, um corpo vivido, não garante que tal encarnação ocorra na es-

$5 \quad$ Trabalhamos tais pontos de forma mais aprofundada no capítulo " $\mathrm{O}$ acontecimento: espectros de em-si enquanto zonas de opacidade" de nossa Tese de Doutorado A Hantologie de Sartre: sobre a espectralidade em $O$ Ser e o Nada. Sob a orientação dos Professores Renaud Barbaras (Paris I) e Marcos Gleizer (UERJ). (Alt, 2017a) fera para-si, que é a esfera imanente purificada: “enquanto nada ou translucidez, o para-si só pode ser estrangeiro a toda exterioridade” (p. 281), conclui. A prova da ausência de encarnação na esfera para-si é evidenciada pela postura de Sartre com relação as experiências próprias ao corpo vivido, como por exemplo, sua recusa da sensação de esforço de Maine de Biran, citada brevemente em O Ser e o Nada. Do mesmo modo, Sartre não contorna, mas inessencializa o fenômeno da dupla sensação já evidenciado por Husserl em Ideias $I I^{6}$, fenômeno que atesta justamente a encarnação do corpo próprio ao tornar sensível o corpo objetivado, privilegiando o tocar (le toucher) à visão, experiência onde "[...] a constituição do corpo próprio se efetua, [no tocar] uma exterioridade espacial surge como minha, um sentir abre (déploie) seu próprio espaço, se encarna” (p. 282). A partir da recusa da originalidade do fenômeno do tocar, Sartre leva então a filosofia da visão a seu extremo, pois além deste modelo pressupor um nada desencarnado em face do mundo, ele faz da encarnação um fenômeno consequente do olhar do outro; outro do mesmo modo transmundano, não situado.

O interessante é que as análises de Barbaras trazem à cena um argumento que contesta o próprio dualismo que sustenta sua crítica: após mencionar o "silêncio" (p. 280) sartriano com relação ao corpo para-si, o autor se volta para a facticidade que atesta o engajamento do para-si no mundo, de um corpo que faz do para-si um ser situado, que não é objeto. Nisto ele menciona a presença de uma afetividade original e da ideia de carne em Sartre como contestação das condições estabelecidas previamente. Pela afetividade original, Sartre mostra que o para-si possui uma apreensão imediata de seu corpo próprio, uma espécie de "gosto de si" (termo de Sartre) que instauraria uma passividade ou um centro de opacidade naquilo que era considerado pura translucidez. Pela ideia de carne é possível apreender a facticidade do corpo do outro diretamente pelo nível fático, que escapa à objetivação. Assim, o corpo do outro se apresenta como corpo vivo, "psiquismo encarnado" no mundo, garantindo ainda a experiência de alteridade fora dos moldes de objetivação do ser-para-outro. Estas surpresas sartrianas, após toda a investida em garantir a experiência do outro pelas condições colocadas acima, deixam Barbaras “perplexo” (p. 293). Ele se pergunta, por exemplo, se a ideia de afetividade original não viria "turvar a consciência" (p. 292) e tornar finalmente inútil ou mais propriamente inadequada as análises do para-outro fundadas na experiência do olhar. No entanto, a seu ver, o "hipercartesianismo" de Sartre é tão forte a ponto de não permitir, mesmo com o surgimento destas novas forças, a implosão do dualismo de base.

É este dualismo que faz Sartre se centrar nas análises do para-outro e da experiência da alteridade pela via da negação interna: a apreensão do outro se dá pelo meu ser-olhado através da experiência da vergonha, a qual confere uma exterioridade ao para-si. O dualismo que se instaura aí é, portanto, entre a esfera

6 Cabestan (2015) diz que, diferentemente de Merleau-Ponty, Sartre não conhecia este texto, o qual durante longo tempo era ainda desconhecido na França. Entretanto, é justamente em oposição à abordagem da corporeidade através do fenômeno da dupla sensação que Sartre irá realizar sua descrição do corpo (p. 158). 
para-si subjetiva e a esfera para-outro objetiva, mediada e possibilitada pelo olhar do outro. No entanto, a terceira condição listada acima mostra a fragilidade do conjunto da teoria do outro sartriana: Sartre coloca o surgimento do outro como um "encontro", de modo que o outro não pode ser deduzido do para-si. Assim, a encarnação do para-si depende de um acontecimento contingente, que por sua vez tem o papel de fundamento da experiência da negação interna, ou seja, do reconhecimento na interioridade de um ser-para-outro. Encontro que coloca em risco a experiência de alteridade de um modo geral: se pode haver certeza no cogito, esta certeza depende de um "acontecimento". Além disso, na medida em que permanecemos numa apreensão centrada no cogito, não há acesso efetivo ao outro, mas somente a uma dimensão estrangeira de si mesmo, como já dito acima. Isto posto, as noções de afetividade original e de carne viriam abalar então as próprias condições estabelecidas por Sartre de modo a tornar a via argumentativa do ser-para-outro inadequada para a compressão da questão do outro. Neste sentido, Barbaras tem razão ao evidenciar o quanto Sartre apostou todas as fichas na experiência do ser-olhado a ponto de não desenvolver suficientemente as consequências desse acesso fático não objetivante atestado pela carne em sua filosofia.

A nosso ver, esse caminho apontado por Barbaras (2000), ao invés de mostrar mais um fracasso de Sartre diante de seu dualismo, faz ao contrário com que o dualismo se enfraqueça diante da evidência dos diferentes níveis de realização da facticidade envolvidos na experiência do outro. Para isso, é necessário então fazer uma distinção entre facticidade e objetividade, também tratada em termos de engajamento e enraizamento por Sartre: enquanto o para-si é engajado no mundo (inscrito pela estrutura imediata da facticidade), o para-outro, como objetivação do engajamento, é enraizado no mundo. Isto significa que o olhar do outro não provoca uma inscrição do para-si no mundo, mas ele objetiva esta inscrição, que é o que Sartre (2012) chama de transcendência-transcendida, que consiste na alienação das estruturas do para-si. O olhar do outro fornece um caráter objetivo ao movimento de transcendência do para-si de maneira que suas "estruturas para-si" adquirem uma forma degradada: o engajamento se torna enraízamento (um "engajamento-objeto" (p. 331)), as possibilidades se tornam probabilidades, etc. "Existir-no-meio-do-mundo-em-presença-dos-outros", diz Sartre, consiste num aprofundamento do engajamento de fato do para-si provocado pela "visibilidade” desta inscrição original. O ser-olhado é assim uma característica que surge ao para-si a partir do olhar do outro, contanto que este para-si já seja desde sempre engajado no mundo. O outro é a "condição concreta e transcendente" (p. 313) da objetividade do para-si e não de sua facticidade. Pelo fato de haver negligenciado a estrutura fática de engajamento do para-si, Merleau-Ponty já confundia facticidade e objetividade, fazendo do para-si um puro nada que não encontra aderência ao mundo. No que diz respeito ao corpo, por exemplo, Sartre esclarece que sua dimensão objetiva não deve ser confundida com sua dimensão fática, embora uma dependa da outra: "o corpo do outro não deve ser confundido com sua objetividade. A objetividade do outro é sua transcendência enquanto transcendida. O corpo é a facticidade desta transcendência. Mas corporeidade e objetividade do outro são rigorosamente inseparáveis" (p. 391). Barbaras, por sua vez, embora ressalte aspectos negligenciados por Merleau-Ponty, não explora as consequências da facticidade do para-si. Porém, ao mostrar as incoerências sartrianas em suas condições, apontando para a carne e a afetividade original como possibilidade de contestar o dualismo e "turvar" a esfera consciente, ele joga Sartre contra Sartre, deixando em aberto novos caminhos de investigação desta filosofia.

\section{A questão do desejo}

Como já se pode notar, o problema do dualismo toma diferentes caminhos na crítica de Barbaras a Sartre. Quanto se trata da questão do desejo, esta base continua operando como ponto de sustentação da crítica, apesar de aqui a diferença aparecer em meio a certa proximidade. Arriscamos ao apontar essa proximidade visto que o movimento do autor se caracteriza finalmente por uma contraposição à concepção sartriana do desejo, mas isso ocorre ao mesmo tempo em que há o reconhecimento de um "passo decisivo" dado por Sartre: o de equivaler o desejo ao movimento intencional da consciência (Barbaras, 2005, p. 115). O artigo "Désir et manque dans L'Être et le Néant : le désir manqué” se concentra sobre esse tema, numa linha anunciada na "Introdução” de Sartre : désir et liberté (livro organizado por Barbaras, que contém o artigo que viemos de citar), de retomada do pensamento sartriano no que diz respeito a sua relação com o movimento fenomenológico na França. Nesta linha, Barbaras (2005) questiona, como citamos brevemente acima, o próprio estatuto fenomenológico da filosofia sartriana na medida em que esta propõe um ser transfenomenal sob o modo do em-si. Porém, as consequências aqui são exploradas na temática do desejo com o intuito de mostrar o quanto esta base prejudica o próprio avanço de Sartre na equivalência entre o desejo e a abertura intencional, ou seja, trata-se de um problema concernente ao "fundamento da abertura do para-si ao em-si, do movimento intencional” (p. 128). Pois, a "versão sartriana da correlação" (p. 118), que consiste no surgimento da consciência pré-reflexiva através da diferenciação para com o em-si, traz necessariamente como consequência a concepção do desejo como falta (manque). Nas palavras de Barbaras:

O desejo designa realmente uma relação constitutiva e não temática ao objeto, de tal forma que a transcendência deste objeto encontra-se preservada nesta própria relação e com isso, ele libera um sentido do sujeito conforme o $a$ priori universal da correlação. No entanto, gostaríamos de mostrar que ao caracterizar o desejo como falta, Sartre perde justamente sua essência e se interdita de pensar a correlação no momento mesmo em que parecia à altura de fazê-lo (Barbaras, 2005, p. 115). 
Em suma, o avanço que representa a abordagem da intencionalidade em termos de desejo é logo gravemente comprometido por uma caracterização do desejo como um tipo de falta, em que a essência do desejo, e com ela a possibilidade da correlação, encontra-se puramente e simplesmente dissolvida (Barbaras, 2005, p. 125).

Em outros termos, ao pensar o em-si de modo finalmente realista, Sartre pode conceber o outro polo da correlação - o sujeito desejante - como uma falta que deve ser preenchida por aquilo que ela não é: no fundo, o sujeito é o nada que buscar ser preenchido pelo ser que ele não é e nunca poderá ser. Novamente, o nada não se encontra aqui em simples posição de "repouso" com relação ao ser, mas sob o modo de uma relação que agora é falta, o que o faz surgir como não sendo esse ser, ou seja, como uma maneira de (não) ser: "Enquanto falta, a negação é somente um avesso de uma posição e não seu outro: ela é a posição diferenciada (différée) e não sua supressão" (2005, p. 123) . A argumentação se complexifica no momento em que Barbaras analisa o "acontecimento absoluto" que é o surgimento do para-si a partir de um "sacrifício" do em-si, palavras utilizadas pelo próprio Sartre. Ao fazer isso, o autor se mostra novamente atento à estrutura da facticidade do para-si (embora não a ressalte nesses termos), mas isso não é o suficiente para que conclua há algum um tipo de “comunidade ontológica” entre para-si e em-si, o que tornaria possível pensar uma teoria do desejo capaz de apreender fenomenologicamente sua essência. Isto porque o artigo, na verdade, traz em conjunto três formas de relação do para-si ao em-si, sem no entanto diferenciá-las suficientemente, a saber: 1) a relação do para-si com o em-si que ele é, que diz respeito ao seu surgimento enquanto "acontecimento absoluto" ou nadificação de si; 2) a relação do para-si com o em-si que ele não é, a qual estabelece as duas faces da intencionalidade que são a negação interna e a posição de um em-si transcendente; 3) a relação do para-si com a totalidade desejada em-si-para-si, que Sartre denomina de ser do valor, o qual não pode ser caracterizado exatamente como um em-si. Estas três relações são abordadas ao longo do texto, mas sem serem explicitadas desta maneira. Isto faz com que Barbaras passe de uma análise do "ato ontológico", primeiro ponto, aos outros dois de forma a estabelecer uma relação entre eles a partir de uma concepção do para-si como nada. Ou seja, a análise do ato ontológico, que é a que atesta a estrutura da facticidade do para-si ou o que "resta do em-si no para-si” (Sartre, 2012, p. 120) não traz visibilidade a este em-si que o para-si sempre é (na medida em que o ato ontológico é incessante nadificação do que se é, e não somente no momento metafísico do surgimento), para que se coloque em questão as conclusões das outras duas relações. Assim, a argumentação se concentra sobretudo na correlação sartriana entre uma pura negatividade e uma pura positividade, prejudicando a teoria do desejo ao tomá-lo como falta a ser preenchida:

Falta ainda precisar as razões desse fracasso, que residem no próprio ponto de partida, quer dizer, nos pressupostos ontológicos que comandam o recurso à teoria da falta a fim de dar conta da relação do para-si ao em-si. Se a correlação é perdida na análise do desejo, é porque ela o é desde o começo. Tudo repousa naquilo que poderíamos nomear de dissimetria ontológica da fenomenologia sartriana, que manifesta uma forma de ingenuidade, quer dizer, de submissão à atitude natural, comprometendo gravemente a démarche fenomenológica. (Barbaras, 2005, p. 135).

Disto podemos dizer que, enquanto a crítica aponta para uma noção de fato problemática do em-si como pura positividade, o mesmo não é válido para o nada enquanto pura negatividade, dada a estrutura da facticidade. Se quisermos tomar alguns dos pontos de Barbaras neste texto, dado que ele mereceria um trabalho detalhado à parte, podemos nos organizar com base nos diferentes tipos de relação que enumeramos acima a fim de iluminar uma questão central, que diz respeito a relação do para-si faltante com o valor, ressaltada por Barbaras como problemática na questão do desejo. Se Sartre parte de uma divisão que é na realidade um "abismo" entre para-si e em si, como o para-si pode desejar uma totalidade que é uma contradição ontológica? Como pode haver desejo sem "horizonte de reconciliação" (2005, p. 132)? A pura positividade do em-si colocada de antemão conduz então à concepção dessa totalidade faltada como um tipo de não ser, visto que é desejo de uma conciliação ontológica impossibilitada pelo dualismo de base. Assim, a natureza da relação intencional estabelecida por Sartre prejudica do mesmo modo a relação do para-si com o valor, ponto recolocado de forma muito clara em Le désir et le monde:

[...] as teorias do desejo que, tal como a de Sartre, reconhecem uma separação no coração do desejo, a levam a termo ao compreendê-la como separação entre dois sentidos distintos do ser o mais opostos possível, em suma entre o nada e o ser. Se o para-si é nada, nos perguntamos como ele poderia desejar este radicalmente outro de si mesmo que é o ser para realizar o si como em-si para-si. (Barbaras, 2016, p. 121)

Para Barbaras (2016), somente uma "comunidade ontológica” entre o desejante e o desejado torna possível compreender o desejo, já que "um desejo de um impossível, é um desejo impossível” (p. 121). O autor pensa, no entanto, que há de fato uma separação entre o desejante e o desejado, mas não se trata de uma separação ontológica que elimina qualquer "pertencimento à mesma terra" (p. 121), trata-se de uma separação que se faz "sob o fundo de uma comunidade que ela não ameaça” (p. 120). Separação é então o termo utilizado por Barbaras como alternativa para se pensar o desejo em termos de falta, noção ainda presa ao paradigma da divisão entre o positivo e o negativo. Por esta mesma razão, não se trata tampouco de uma concepção do desejo como afirmação, a qual encontra-se a seu ver ainda presa aos moldes substancialistas de colocar a questão: 
“a alternativa não é entre o negativo e o positivo, como se o sujeito do desejo só pudesse ser ou privado ou completo, vazio ou cheio [...] para além do vazio e do cheio, da falta e do conatus, há a separação” (p. 119). Ao conceber o desejo como falta, Sartre faz jus então à sua concepção substancialista de negatividade, apesar de diferenciar, embora não sem deslizes, a falta da necessidade (besoin), esta última normalmente atrelada à ideia de um sujeito que seria "privado" de algo 7 .

A questão é que arriscamos em dizer que esta crítica se faz em meio a certa proximidade, que estabelece também sua distância. Um ponto dessa proximidade, como já mencionamos, é levantado pelo próprio Barbaras (2005) ao celebrar a identificação feita por Sartre entre desejo e intencionalidade: o desejo como a abertura mesma de um sujeito a outro que não ele, como aquilo que condiciona a aparição de um mundo. Acrescentamos outros pontos: Na filosofia de Barbaras, mesmo não sendo falta, o desejo é "absolutamente insaciável”, pois ele não diz respeito ao fato de "ter" algo, mas o desejo, assim como para Sartre, é desejo de ser, mais especificamente, desejo de ser si: "[...] o desejo é desejo de si, aspiração a ser, questão ontológica” (Barbaras, 2016, p. 117). Aqui também encontramos que o ser desejante, mesmo que nada lhe falte, não é por isso pleno, ele é "caracterizado por uma incompletude fundamental, por uma insuficiência de ser (défaut d'être), e é por isso que nada pode lhe preencher" (2016, p. 118). O desejo é ainda "o movimento pelo qual um sujeito tende a se apropriar de seu ser, a reencontrar-se consigo mesmo", o sujeito encontra-se, portanto, fora de si, é um sujeito "exilado" (p. 118). Estas últimas afirmações nos apontam para a afinidade presente nas duas concepções que pensam um sujeito incompleto, que busca ser si fora de si, sendo que esta busca é insaciável; assim como para a distinção entre o desejo e a necessidade e a consideração da questão do desejo num plano ontológico ${ }^{8}$. Porém, como marcamos brevemente, o posicionamento dualista de Sartre não permitiria, aos olhos de Barbaras, pensar como o exílio instaurado pela separação de si só é possível havendo o pertencimento atestado pela comunidade ontológica dos modos de ser em jogo na correlação fenomenológica. Resta saber, a partir da retomada da questão da facticidade em Sartre, estrutura que impede a concepção do para-si como puro nada e que contesta o dualismo, quais seriam ainda as implicações da concepção do desejo como falta, assim como de que modo a carne garantiria a efetiva experiência do outro, a fim de recolocar em questão as afinidades e oposições entre os dois autores.

\section{Referências}

Alt, F. (2017a). A hantologie de Sartre: sobre a espectralidade em O Ser e o Nada. (Tese de Doutorado). Universidade do Estado do Rio de Janeiro e Paris 1 Panthéon-Sorbonne.

$7 \quad$ Cf. Barbaras, 2016, p. 119; 2005, p. 127; p. 132, p. 134

8 Embora Barbaras parta de uma fenomenologia para uma ontologia e Sartre faça o contrário.
Alt, F. (2017b). Limites da crítica de Merleau-Ponty a Sartre em O Visível e o Invisível. Ekstasis: Revista de Hermenêutica e Fenomenologia 6 (1), 51-65.

Barbaras, R. (2000) Le corps et la chair dans la troisième partie de L'être et le néant. Em Mouillie, J-M. (Org.) Sartre et la phénoménologie. Fontenay-aux-Roses: ENS. 279-296.

Barbaras, R. (2001). De l'être du phénomène. Grenoble: Jérôme Millon.

Barbaras, R. (2005). Désir et manque dans Lêtre et le néant: le désir manqué. Em: Barbaras, R.(Org) Sartre: désir et liberté. Paris: PUF.

Barbaras, R. (2009). La perception: essai sur le sensible. 2. ed. Paris: Vrin.

Barbaras, R. (2013). Dynamique de la manifestation. Paris: Vrin.

Barbaras, R. (2016). Le désir e le monde. Paris: Hermann.

Cabestan, P. (2015) Qui suis-je ? Sartre et la question du sujet. Paris: Hermann.

Heidegger, M. (2008). Lettre sur l'humanisme. In Questions III et IV. Paris: Gallimard. (Trad. A. Préau)

Husserl, E. (2013) Idées directrices pour une phénoménologie et une philosophie phénoménologiques pures. Tome premier : Introduction générale a la phénoménologie pure. Paris: Gallimard. (Trad. P. Ricœur).

Merleau-Ponty, M. (2013). Le visible et l'invisible. Paris: Gallimard.

Sartre, J-P. (1989). Situations I: essais critiques. Paris: Gallimard.

Sartre, J-P. (2012). L'être et le néant. Paris: Gallimard.

Fernanda Alt é Doutora em Filosofia pela UERJ (com bolsa CAPES) e Paris I Panthéon-Sorbonne (Cotutela) com Renaud Barbaras cujo trabalho foi, em 2018, agraciado com o Prêmio CAPES de Tese de Filosofia. Ela é também Mestre em Psicologia Social pela Universidade do Estado do Rio de Janeiro com auxílio CAPES, orientada por Marcos Gleizer. Possui graduação em Psicologia pela Pontifícia Universidade Católica do Rio de Janeiro (PUC-Rio). Tem experiência clínica e docente na área de Psicologia fenomenológica-existencial e concentra sua pesquisa na área da Filosofia Francesa Contemporânea com foco na Fenomenologia, sobretudo no pensamento de Jean-Paul Sartre. Atualmente é Pós-Doutoranda UFSCar (Bolsista FAPESP 2017/24307-9). E-mail: fernandaalt@gmail.com 